\title{
Correction to: Future changes in Atlantic hurricanes with the rotated-stretched ARPEGE-Climat at very high resolution
}

\author{
Fabrice Chauvin ${ }^{1}$ (I) $\cdot$ Romain Pilon ${ }^{2} \cdot$ Philippe Palany $^{2} \cdot$ Ali Belmadani $^{2}$
}

Published online: 14 January 2021

๑) Springer-Verlag GmbH Germany, part of Springer Nature 2021

\section{Correction to: Climate Dynamics (2020) 54:947-972 https://doi.org/10.1007/s00382-019-05040-4}

In the original version of the article contained errors in the panel labels of Figs. 8 and 10. The correct Figs. 8 and 10 is given in this correction article.

The original article can be found online at https://doi.org/10.1007/ s00382-019-05040-4.

Fabrice Chauvin

fabrice.chauvin@meteo.fr

1 Centre National de Recherches Météorologiques, Météo-

France/CNRS, Meteo-France 42 avenue G. Coriolis,

31057 Toulouse Cedex 1, France

2 Direction InterRégionale Antilles-Guyane, Météo-France,

Fort-de-France, France 

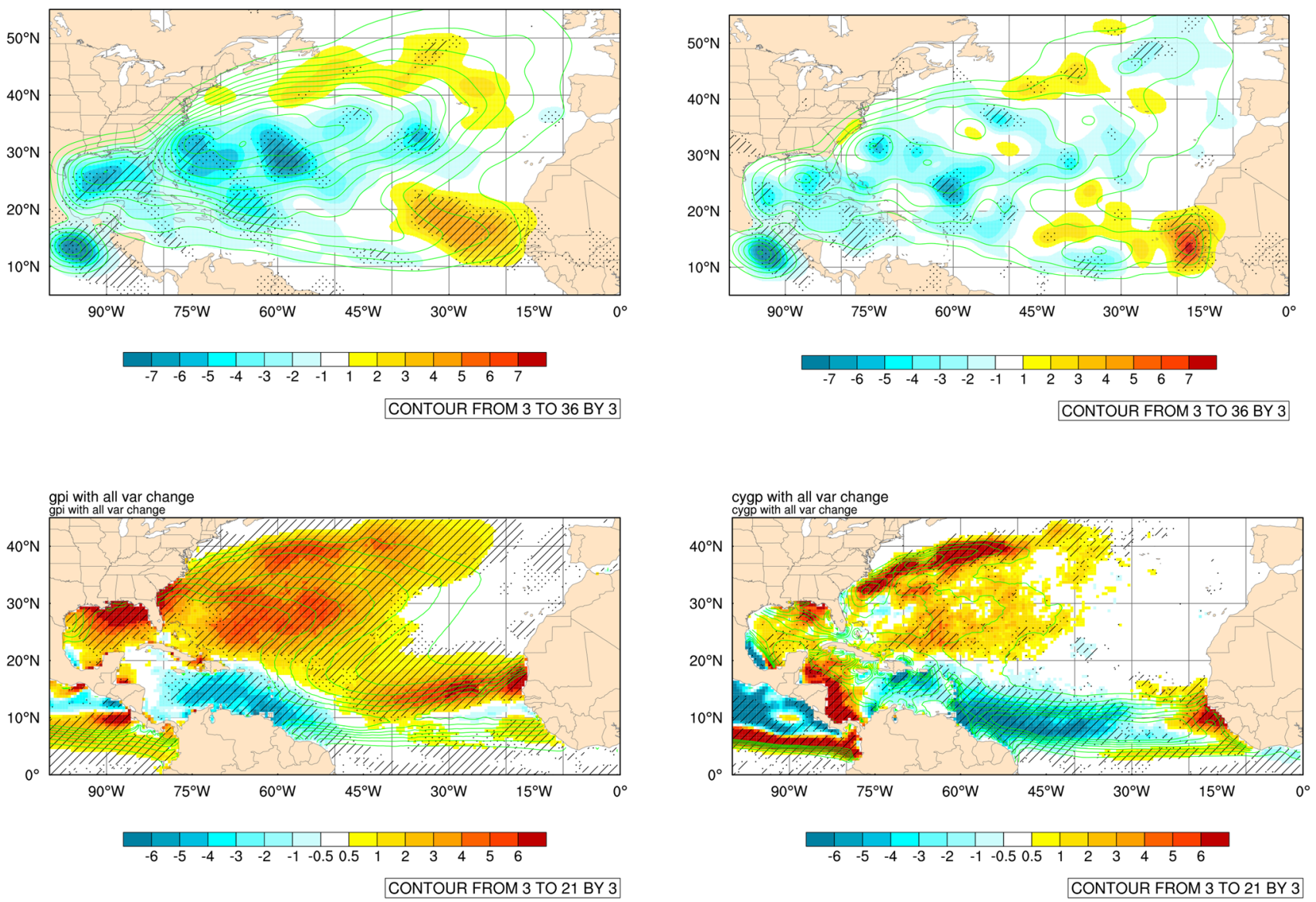

Fig. 8 Top: Changes in the annual number of TC days (left) and TC genesis (right) densities between the future (AMIP-RCP85) and the present (AMIP-HIST) climate. Units are number of TC days per 20 years (left) or genesis per 50 years (right) by $5^{\circ} \times 5^{\circ}$ square area.

Bottom: Changes in the GPI (left) and CYGP (right) for the JulyNovember season. Mean present climatology is reported as green contours. Dots and hatchings are for 95 and $99 \%$ significance levels respectively. Units are genesis pre 50 years per $5^{\circ} \times 5^{\circ}$ square area 

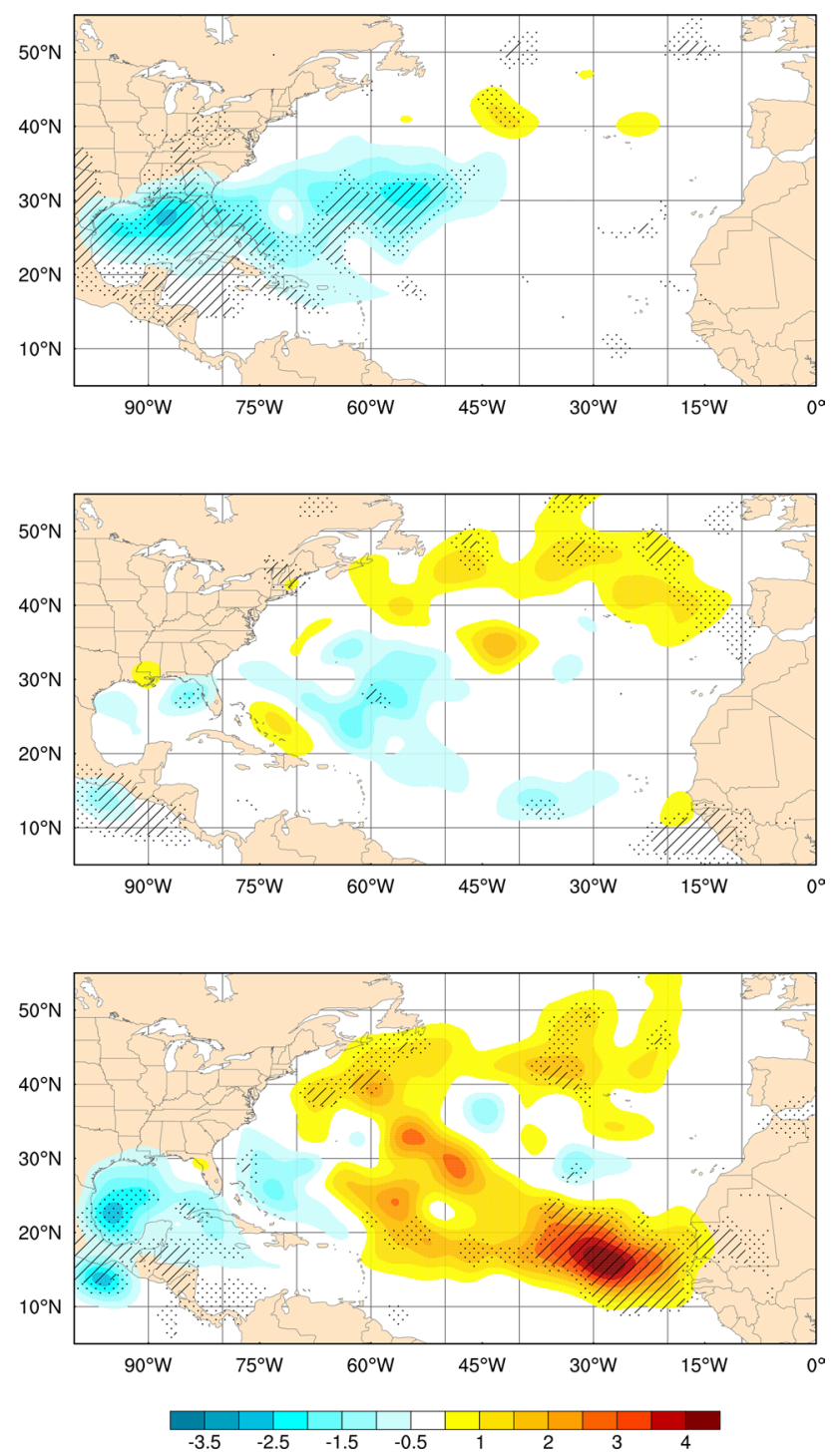

Fig. 10 Changes in the TC days between the future (AMIP-RCP85) and the present (AMIP-HIST) climate for months of July (top), August (middle) and September (bottom). Units are number of TC days per 20 years per $5^{\circ} \times 5^{\circ}$ square area. Dots (resp. hatching) are for 95\% (resp. 99\%) significance level

Publisher's Note Springer Nature remains neutral with regard to jurisdictional claims in published maps and institutional affiliations. 